\title{
Research on Balanced Allocation of Urban and Rural Public Resource under Guidance of Marx's Theory of Urban-rural Relation
}

\author{
Ying Ji \\ Oxbridge College, Kunming University of Science and Technology, Kunming 650000, China
}

Keywords: Marx; theory of urban-rural relation; urban and rural public resource; balanced allocation

\begin{abstract}
Currently, there exists imbalanced allocation of public resource in China's rural and urban area; for a long time, the public resource allocation obtained in urban area is far higher than that in rural area. However, China has a not abundant public resource, and how to carry out balanced allocation of poor materials in rural and urban area is worth researching. According to the practical activities, Marx has given a systematic explanation on urban-rural relation, and this paper carries out research on the balanced allocation of urban and rural public resource in China under the guidance of this theory.
\end{abstract}

\section{Introduction}

Currently, the core problem of China's urban-rural relation is about which way is applied to realize effective allocation and circulation of resource in urban and rural area under the condition of shortage of resource and then realize overall social progress. Marx, Engels, Lenin, and Stalin have established comprehensive and systematic theory of urban-rural relation in their theories and practical activities, and such theory is the scientific theory used to guide, research, and handle the balanced allocation of urban and rural public articles in China. The balanced allocation of urban and rural public articles is to seek for the integration of urban and rural supply mode in the urban and rural separated supply mode, and promote the coordinated progress of urban-rural relation in social life through the integration of urban and rural supply mode. The balanced allocation of public resource is always a critical problem of China's urban-rural relation; because China is under the primary stage of socialism, the public resource is relatively deficient, and the allocation and supply of public articles for rural area are always worse than that for urban area, which is an indisputable fact; due to the existence of such situation, many problems happen in the urban-rural relation. Marx and Engels have comprehensively and systematically explained the balanced allocation of urban and rural public resource through practical activities and have formed a theory which can guide China to effectively solve the problem of improving the allocation of public resource in urban-rural relation.

\section{Introduction of Marx's theory of urban-rural relation}

\section{Marx's theory of urban-rural relation}

In the process of historic development, the urban and rural areas are gradually formed with the continuous progress and development of political and economic activities in the society, and they originally appear as a kind of social community. However, their separation is caused due to division of labor in the society. The appearance of division of labor promotes the development of productivity, and also promotes the separation between agricultural work and industrial work, which causes separation of urban and rural area. Through overview on historical development process of urban-rural relation, it can be found that the urban-rural relation has undergone a process from integration to separation, and then integration. However, at very early time, the urban area has no independent economic function, and it is fully uniform with rural area. The continuous development of commodity economy causes clearer and clearer division of labor, more and more obvious respective features of urban and rural areas, and less and less mutual correlation; at last, they form independence and separation. If the division of labor appears in the internal part of one nationality, the separation between commercial work and agricultural work appears at the earliest time, which has 
been clearly stated in Marx's The German Ideology. The separation between different works finally results in the opposition of interests of urban and rural areas; the residents are divided into two different classes, and the urban and rural areas have completely opposite features. In Marx's opinion, the urban-rural relation affects the overall situation of social life; in case of change in urban-rural relation, the corresponding change will happen in whole society due to this change; in order to realize communism, it is required to completely eliminate urban and rural separation, eliminate the difference in industrial and agricultural work, and eliminate the difference in brainwork and physical labor. Marx's theory of urban-rural relation explains that the opposition of urban-rural relation hinders social development, and it is also a not harmonious factor in the society. In order to realize social development, it is required to break urban-rural separation and promote urban-rural integration. In the Marx's theory of urban-rural relation, it gives suggestive measures as follows: combine industry with agriculture to promote disappearing of urban-rural opposition; carry out free education for all children regardless of whether they are urban or rural children. However, there is specific reason for existence of urban-rural separation, and such state can't be eliminated within short time. The urban-rural integration can't be realized in one day, and it must be a long process.

\section{Enlightenments from Marx's theory}

Through understanding of Marx's theory, we can know that the final purpose of the development of urban-rural relation is to realize urban-rural integration. The appearance of urban-rural separation is the product of one stage in the process of social development; however, this situation will gradually disappear with the development of social productive force, continuous development of industry and agriculture, and continuous improvement of cultural, economic, and political ability in rural area, and the urban-rural integration will certainly appear while the social development reaches certain stage. Marx's theory of urban-rural relation is the theoretical guidance for China to carry out allocation of urban and rural public articles; through this theory, we can see the development mode of urban-rural relation in the future. Although each country will face urban-rural relation and have different solutions, the basic principle remains unchanged. Marx's theory of urban-rural relation is established under the background of capitalist era, but its opinions and methods can be widely applied; even in China's socialist society, we can only combine this theory with China's actual situation to handle problems from perspective of development, clearly know the actual situation of China's development of urban-rural relation, and keep continuous exploration in practice. Through taking Marx's theory of urban-rural integration as guidance, it is able to promote the development and China's urban and rural economy and finally realize the purpose of urban-rural integration via long-term efforts.

\section{Marx's theory of urban-rural relation provides the basis for allocation of urban and rural public resource in China.}

The so-called public resource is the resource which is opposite to private resource, provided by the government and used to meet the production and living demand of social members, and this resource can promote the development of social members. From perspective of society, the public resource includes national compulsory education and social security, etc. In order to realize urban-rural integration, it is required to firstly carry out balanced allocation of urban and rural public resource. Marx thinks that the opposition of urban-rural relation is a serious barrier in social development; although promoting the integration of urban-rural relation is a long process, it is a result which can be certainly realized. As for China, the urban-rural dual structure still exists, and the allocation of public materials is inclined to urban area. The social resource such as medical institution and education institution in urban area is much better than that in rural area, and the difference in urban and rural public resource still exists; furthermore, China's current policies and systems also require to allocate more public resource to urban area. In order to change this situation and gradually narrow the gap in urban and rural public resource, we shall firstly cancel the legal rules. The inequality between urban and rural area shall be gradually eliminated; through eliminating inequality in policies and treatment, we can realize reasonable and fair allocation of resource. According to Marx’s theory of urban-rural 
relation, we can know that the final purpose of China's balanced allocation of urban and rural public resource is not to carry out indistinctive equal allocation for all public resources, but to take "sublation" as basis to firstly carry out equal allocation of materials of public foundation and then carry out more equal allocation under the condition of continuous development of China's industrialization and urbanization according to China's actual condition.

\section{Exploration on balanced allocation of China's urban and rural public resource under guidance of Marx's theory of urban-rural relation}

\section{Development rule of urban-rural relation}

It is pointed out in Marx's theory of urban-rural relation that the requirement of balanced allocation of urban and rural public resource will appear while the social development enters into certain period; the appearance of this requirement is the inevitable trend of social development, and it also shows that the development of urban-rural relation enters into a new stage. Obviously, China is just under this period; the urban-rural relation shall be urgently improved, and the urban-rural dual structure seriously hinders China's social development. To promote urban-rural integration is a long process; however, at current stage, the wisest choice is to gradually narrow the difference in the allocation of urban and rural public materials and continuously improve urban-rural relation. As two kinds of social systems, the urban and rural difference is not only reflected at economy, but also reflected at culture and politics, and those differences are gradually formed. Marx thinks that the internal contradiction is the most essential reason which promotes the development of things; the urban-rural relation has a completely same development rule with the thing, and both of them have a morphologic change from low level to high level. In the earliest period of human social development, while the division of labor doesn't appear, the social productivity is low, the agriculture and animal husbandry are integrated together, and there is no difference in different labors, and no difference in urban and rural area in the society. However, with continuous development of human society, the productive force is improved, and the division of labor appears, which promotes the development of productive force, the difference in industrial and agricultural work, and the separation between industry and agriculture, thus the cities are gradually formed and the separation between urban and rural area is formed. While the division of labor enters into deeper development, the new integration is formed between urban and rural area, and the opposite situation completely disappears. Some people not only engage in industrial work, but also participate in agricultural work, and there is no existence of two different classes. According to the assumption of Marx's theory of urban-rural relation, in the future society, the old state apparatus will disappear, and the private ownership will gradually disappear without difference in class and labor; in the society, it is able to truly realize harmonious relation between people, and each person can realize free development in the society. The urban-rural separation certainly appears in the society; meanwhile, the process from urban-rural separation to urban-rural integration is also an inevitable requirement for social development.

\section{Analysis on balanced allocation of public resource in China}

Before establishment of new China, the urban-rural relation in China was completely opposite. Later, the old state apparatus was broken and the new China was established. However, due to little exertion of economic function, the social productivity was low and there was no integration of urban-rural relation. After 1978, China implemented household contracted responsibility system, which promoted the reform of rural economy; in later period, the reform also happened in urban economic system, all of which promoted mutual penetration of urban and rural area and realized urban-rural integration. Due to not coordinated urban and rural economic development, the urban and rural separation appeared again after 1980s; the cities can't accept more surplus rural labor force, and many social issues also became prominent. Through research on Marx's theory of urban-rural relation, we know that there will be larger and larger difference in urban and rural system if China continues to execute original allocation system of public materials at current stage, which will not help the urban and rural harmonious economic development and intensify their separation. A good 
interaction has been realized in China's urban and rural area; the rural industrialized development mode in 1970s and the urban-rural mode in 1990s take the market as intermediary; till now, the urban-rural relation is deepened. China's development of urban-rural relation also deeply reflects China's social development. The supply of urban and rural public materials reflects the urban and rural development rule. Currently, China is just under the primary stage of socialism, and the urbanization and industrialization are under synchronous development. Therefore, in order to promote full development of China's society, we shall pay attention to the development of urban-rural relation; instead of treating them as two kinds of different social systems, we shall enhance their correlation and make them depend on each other; the urban and rural public materials shall be uniformly supplied to realize the uniform allocation of urban and rural resource, uniform compulsory education, uniform medical care, uniform infrastructure, uniform social security system, and uniform social treatment, etc. As long as we place urban and rural area into uniform system, carry out balanced allocation of public resource, establish their equal relation, enhance their tight relation, and make their relation develop toward harmonious and balanced direction, it is able to make the urban and rural gap become less and less, and then their opposition can gradually disappear. The reform of urban-rural relation requires to carry out balanced allocation of urban and rural public resource, which is the inevitable requirement of social development, and also the inevitable requirement while the urban-rural relation is developed to certain stage.

\section{Conclusion}

In conclusion, through research on Marx's theory of urban-rural relation, we have known that China is just under the important period of transition of urban-rural relation; in order to continuously promote social development, we shall improve the urban-rural relation and promote the development of urban-rural integration. In order to promote urban-rural integration and social development, we shall continuously narrow urban and rural gap, place them into uniform system, and carry out balanced allocation of urban and rural public resource so as to continuously promote the development of rural economy, improve urban-rural relation, enhance their relation, and make urban and rural area depend on each other and realize a harmonious development. At current stage, to carry out balanced allocation of China's urban and rural public resource is the inevitable requirement of development of urban-rural relation, and also the intrinsic necessity of social development.

\section{References}

[1] Li Chuanbin, Yu Sinian, Chen Haoran: Thought of Marx's Urban-rural Relation and Its Practice in Contemporary China, Socialism Studies, 2012 (04).

[2] Wang Zhongwu: Triple-Construction Mechanism of Urban-rural Relation in Contemporary China, Academic Monthly, 2012 (12).

[3] Yao Yongming: Contemporary Interpretation and Practice of Marx and Engels's Thought of Urban-rural Integration, Journal of China Youth College for Political Sciences, 2012 (03).

[4] Li Chuanbin, Yu Sinian, Chen Haoran: Thought of Marx’s Urban-rural Relation and Its Practice in Contemporary China, Socialism Studies, 2012 (04).

[5] Zhang Yongyue: Problems Faced in China's Urban-rural Integration and Development Ideas, Journal of East China Normal University (Philosophy and Social Sciences Edition), 2011 (01). 